\title{
Preparation of Activated Carbon From Sunflower Straw by H3PO4 Activation and Its Application for Acid Fuchsin Adsorption
}

\section{Wende Zhao}

Inner Mongolia Normal University

Liping Chen ( $\nabla$ clp@imnu.edu.cn )

IMNU: Inner Mongolia Normal University

\section{Research Article}

Keywords: Sunflower straw, Phosphoric acid activation, impregnation ratio, Activated carbon, Adsorption, Acid fuchsin

Posted Date: July 26th, 2021

DOI: https://doi.org/10.21203/rs.3.rs-658385/v1

License: (c) (i) This work is licensed under a Creative Commons Attribution 4.0 International License.

Read Full License 


\section{Preparation of activated carbon from sunflower straw by}

\section{$2 \mathrm{H}_{3} \mathrm{PO}_{4}$ activation and its application for acid fuchsin}

\section{3 adsorption}

4 Wende Zhao ${ }^{1,2} \cdot$ Lipng Chen ${ }^{1,2}$

\section{Abstract}

In this work, sunflower straw (SS) was used as the raw material, $\mathrm{H}_{3} \mathrm{PO}_{4}$ was used as the activator, and the sunflower straw activated carbon (SSAC) was prepared by the one-step activation method under the impregnation ratio of 1:1, 1:2, 1:3, 1:5 $\left(\mathrm{SS} / \mathrm{H}_{3} \mathrm{PO}_{4}, \mathrm{~g} / \mathrm{g}\right)$. The adsorption of acid fuchsin (AF) simulated dye wastewater by SSAC prepared under different immersion ratios has been studied. As the impregnation ratio increases, the pore structures of SSAC changed greatly. SSAC3 had the largest specific surface area $\left(1794.01 \mathrm{~m}^{2} / \mathrm{g}\right)$, and SSAC4 had the smallest microporosity $\left(0.0527 \mathrm{~cm}^{3} / \mathrm{g}\right)$ and the largest pore volume $\left(2.549 \mathrm{~cm}^{3} / \mathrm{g}\right)$. The adsorption kinetics of four types of SSAC to AF were more in line with the quasi-second-order adsorption kinetic model. The Langmuir isotherm model was suitable for describing SSAC3 and SSAC4, and the Freundlich isotherm model was suitable for describing SSAC1 and SSAC2. Thermodynamics showed that the adsorption process was spontaneous and endothermic. At $303 \mathrm{~K}$, SSAC4 showed a removal rate of $97.73 \%$ for $200 \mathrm{mg} / \mathrm{L} \mathrm{AF}$, and the maximum adsorption capacity of $2763.36 \mathrm{mg} / \mathrm{g}$, which was the highest among the four types of SSAC. This study shows that the sunflower straw activated carbon prepared by the $\mathrm{H}_{3} \mathrm{PO}_{4}$ one-step activation method is a green and efficient carbon material and has great application potential in the treatment of dye-containing wastewater.

Key words Sunflower straw $\cdot$ Phosphoric acid activation · impregnation ratio $\cdot$ Activated carbon Adsorption $\cdot$ Acid fuchsin

Corresponding author

Liping Chen

clp@imnu.edu.cn

${ }^{1}$ Chemistry and Environment Science College of Inner Mongolia Normal University, Hohhot 010022, China

${ }^{2}$ Key Laboratory of Environmental Chemistry of Inner Mongolia, Hohhot 010022, China 


\section{Introduction}

The application of dyes is very common in the industry fields of textiles, printed matter, rubber, plastics, cosmetics and so on. The annual production of dyestuff in the world exceeds $7 \times 10^{5} \mathrm{t}$ (Zhang et al. 2011), resulting in a large amount of dyestuff wastewater containing toxic chemicals, carcinogenic substances, which is difficult to biodegrade (Greer et al. 2015; Radjenovic et al. 2015). Unfortunately, these colored dyes will seriously reduce the light transmittance of water, thus blocking the photosynthesis of aquatic plants (Yang et al. 2015a). Triphenyl methane dye is one of the three most used dyes (azo dye, anthraquinone dye, and triphenyl methane dye) (Liu et al. 2021). Acid fuchsin (AF), as a typical dye of triphenyl methane, has been used as inhibitor of reverse transposition of immunodeficiency virus (Baba et al. 1998), corrosion inhibitor of copper (Bastidas et al. 2003), reverse selective bacteriostatic agent (Burke and Skinner 1924) and laboratory reagent (Dutta and Basu 2014). It is necessary and urgent to remove AF from wastewater.

At present, the methods for removing wastewater mainly include physical adsorption (Zhang et al. 2020b; Renita et al. 2019), chemical oxidation (Yang et al. 2014; Sheng et al. 2010), and biological method (Tabaraki and Sadeghinejad 2017; Gao et al. 2018). Due to the advantages of simple operation, low cost, large amount of treatment, and few toxic and harmful residues produced after treatment, the approach of physical adsorption has been widely used in the treatment of dye wastewater (Putra et al. 2009; Yang et al. 2020). The choice of adsorbent is an important factor to determine the adsorption performance. For the adsorption of AF, the adsorbents include activated carbon (AC) (Zhou et al. 2019), nanocomposite materials (Rahnama et al. 2018) and gel (Zhang et al. 2020a). Particularly, AC is the most widely used and effective absorbent due to their large specific surface area, large pore volume, abundant surface functional groups and aromaticity (Peiris et al. 2017; Song et al. 2017; Zhou et al. 2019). Moreover, there are a wide range of raw materials, such as agricultural and forestry wastes (Wang et al. 2018), lignin (Vladov et al. 2019), leather wastes (Kong et al. 2014), etc., to prepare the excellent AC with high pore and specific surface area by physical or chemical methods. Compared with physical approach, chemical method has lower synthesized temperature and time (Ahmed 2016), and the prepared AC has larger specific surface area and controllable microporosity in a small range (Ahmed 2017). The activators used for chemical activation usually include $\mathrm{KOH}, \mathrm{ZnCl}_{2}, \mathrm{H}_{3} \mathrm{PO}_{4}$. To ensure porosity, air or nitrogen can be introduced during the pyrolysis process. (Vladov et al. 2019). Since $\mathrm{ZnCl}_{2}$ might pollute the environment, $\mathrm{H}_{3} \mathrm{PO}_{4}$ becomes a more popular activator (Teng et al. 1998). In comparison, the $\mathrm{H}_{3} \mathrm{PO}_{4}$ activation method has the advantages of simple one-step method, low activation temperature, short activation time, high yield, large specific surface area and high mesoporous rate (Reffas et al. 2010), thus, the obtained high mesoporous materials have better adsorption performance for the dyes in the wastewater with macromolecules (Patidar and Vashishtha 2020).

As a large agricultural country, China produces a large amount of agricultural waste every year, and sunflower straw is one of the main sources. Taking September 2016 as an example, Chinese production is about 175.8 million tons of sunflower seeds, and 527.4 million tons of sunflower stalks could be produced according to the ratio of the output of sunflower stalks to sunflower in China (Zhang et al. 2017). Most of these stalks are burned and deposited as farmland fertilizer, but the resulting $\mathrm{PM}_{2.5}, \mathrm{SO}_{\mathrm{x}}$ and $\mathrm{NO}_{\mathrm{x}}$ will pollute the atmosphere (Yang et al. 2020). 
Therefore, using sunflower straw waste to prepare biomass activated carbon can not only reduce environmental pollution, but also further develop the economic benefits and utilization potential of sunflower straw to achieve the purpose of waste treatment. In this study, sunflower straw was used as raw material, $\mathrm{H}_{3} \mathrm{PO}_{4}$ was used as activator, and SSAC was prepared by one-step activation method at the impregnation ratio of 1:1 to 1:5. To characterize SSAC, investigate the surface physical and chemical properties of SSAC. The adsorption kinetics, isothermal adsorption equilibrium and thermodynamics methods were used to study the properties of SSAC prepared at different impregnation ratios and its effect on $\mathrm{AF}$ adsorption and adsorption properties.

\section{Materials and methods}

\section{Materials}

Sunflower straw was collected from Hetao Plain, Inner Mongolia Autonomous Region, China. Reagents: phosphoric acid $\left(\mathrm{H}_{3} \mathrm{PO}_{4}, 85 \%\right.$, Shanghai United Chemical Plant), acid fuchsin $\left(\mathrm{C}_{20} \mathrm{H}_{17} \mathrm{~N}_{3} \mathrm{Na}_{2} \mathrm{O}_{9} \mathrm{~S}_{3}, \lambda_{\max }=545 \mathrm{~nm}\right.$, Tianjin Tianxin Fine Chemical Development Center $)$, hydrochloric acid ( $\mathrm{HCl}, 36 \%$ 38\%, Chengdu Kelong Chemical Co., Ltd.), all reagents were analytical pure, and all solutions were prepared with ultra-pure water.

\section{Preparation of SSAC}

Sunflower straw was cleaned with tap water, then rinsed with pure water for 3-4 times, and then put into the oven to dry completely at $115^{\circ} \mathrm{C}$. Break the completely dried sunflower straw into small pieces and grind it in the grinder. Put the grinded straw powder through a 90-mesh sieve and put it into a plastic sealed bag. Weighed 4 portions of straw powder, each $15 \mathrm{~g}$, into 4 crucibles, added different amounts of $85 \%$ concentrated phosphoric acid, and adjusted the impregnation ratio to $1: 1,1: 2,1: 3$ and 1:5. Stirred fully, sealed it with plastic wrap and stood for $12 \mathrm{~h}$, then put it into an electric blast drying oven and heated it for $150 \mathrm{~min}$ at $180{ }^{\circ} \mathrm{C}$. After being cooled to room temperature, placed in a tube furnace with $10{ }^{\circ} \mathrm{C} \cdot \mathrm{min}^{-1}$ in the heating rate in $\mathrm{N}_{2}$ protection under the $600{ }^{\circ} \mathrm{C}, 150 \mathrm{~min}$ activation, the 4 samples after cooling were washed with ultrapure water and supplemented with $0.1 \mathrm{~mol} / \mathrm{L} \mathrm{NaOH}$ solution until the $\mathrm{pH}$ was neutral. They were dried in an oven at $85^{\circ} \mathrm{C}$ for $2 \mathrm{~h}$, then crushed with a mortar and passed through a 60-mesh sieve. The four types of SSAC obtained were marked as SSAC1, SSAC2, SSAC3 and SSAC4, and they were put into plastic bags for use.

\section{Characterization methods of SSAC}

The elemental composition of materials was detected by an elemental analyzer (Costech ECS 4010/4024, Italy). The morphology of the material was characterized by scanning electron microscope (SEM, HITACHI SU8010, Japan). Specific surface and pore size characteristics were determined at $77 \mathrm{~K}$ using an automatic specific surface area and pore size analyzer (Micromeritics ASAP2460, USA) using $\mathrm{N}_{2}$ as adsorbent. The functional groups of the materials were determined by Fourier infrared spectroscopy (FT- IR, Nicolet6700, USA).

\section{Adsorption experiment}

In this study, batch measurement method was used to investigate the adsorption effect of self-made $\mathrm{AC}$ on $\mathrm{AF}$, and different adsorption thermodynamic equation and adsorption kinetic 
equation were selected for fitting. AF removal rate $(\%)$, equilibrium adsorption capacity $\left(q_{\mathrm{e}} /\right.$ $\left.\mathrm{mg} \cdot \mathrm{g}^{-1}\right)$ and adsorption capacity $\left(q_{\mathrm{t}} / \mathrm{mg} \cdot \mathrm{g}^{-1}\right)$ at time $t(\mathrm{~min})$ were calculated by the following equation:

$R(\%)=\frac{\left(C_{0}-C_{t}\right)}{C_{0}} \times 100 \%$ (1)

$q_{e}=\frac{\left(C_{0}-C_{e}\right) V}{m}(2)$

$q_{t}=\frac{\left(C_{0}-C_{t}\right) V}{m}$ (3)

where $C_{0}(\mathrm{mg} / \mathrm{L}), C_{\mathrm{t}}(\mathrm{mg} / \mathrm{L})$ and $C_{\mathrm{e}}(\mathrm{mg} / \mathrm{L})$ are the initial, at time $t(\mathrm{~min})$ and equilibrium concentrations of AF solutions, $V$ is the volume of AF solution (L), and $m$ is the SSAC amount $(\mathrm{g})$. $1000 \mathrm{mg} \cdot \mathrm{L}^{-1}$ acid fuchsin reserve solution was prepared for later use. Because AF will fade with the increase of $\mathrm{pH}$, in order to reduce the influence of its own fading, the tests are all carried out under the condition of the initial $\mathrm{pH}$ of $\mathrm{AF}(\mathrm{pH}=2.89)$.

Adsorption kinetics experiment: pipetted $50 \mathrm{~mL}$ of the $200 \mathrm{mg} / \mathrm{L}$ AF solution prepared with the stock solution and separately mixed with $0.05 \mathrm{~g}$ of 4 types of SSAC in a conical flask with rubber stopper, and put them in a constant temperature water bath shaker at $303 \mathrm{~K}, 120 \mathrm{rpm}$. Shook for $240 \mathrm{~min}$ under dark conditions (time interval 5-20 min), took the supernatant and filter, and measured the filtrate with an ultraviolet spectrophotometer (UV-2600, Tianmei, China) at $\lambda_{\max }$ $=545 \mathrm{~nm}$.

Adsorption thermodynamics experiment: respectively weighed $0.025 \mathrm{~g}$ of 4 types of SSAC into a conical flask with rubber stopper, and then added $25 \mathrm{~mL}$ of $200-1000 \mathrm{mg} / \mathrm{L}$ acid fuchsin solution prepared with stock solution, mixed and placed it in a constant temperature water bath to shake vibrate at $293 \mathrm{~K}, 298 \mathrm{~K}, 303 \mathrm{~K}, 120 \mathrm{rpm}$ for $4 \mathrm{~h}$ under dark conditions, filter and measure with UV spectrophotometer.

\section{Results and discussion}

\section{Element analysis of SSAC}

Elemental analysis was performed on four SSAC samples, and the specific data were shown in Table 1. The data showed that the main elements of SSAC were $\mathrm{C}(60.33 \%-67.34 \%)$ and $\mathrm{O}$ (30.73\%-38.15\%), and the content of $\mathrm{H}(1.35 \%-1.54 \%)$ and $\mathrm{N}(0 \%-0.39 \%)$ was very low. When the impregnation ratio increased from $1: 1$ to $1: 3$, the $\mathrm{C}$ content in the three types of SSAC increased with the increase in the impregnation ratio, while the $\mathrm{O}$ content decreased. When the impregnation ratio was $1: 3$, the highest $\mathrm{C}$ content $(67.34 \%)$ and the lowest $\mathrm{O}$ content $(30.73 \%)$ were reached, indicated that the use of $\mathrm{H}_{3} \mathrm{PO}_{4}$ as an activator can remove oxygen-containing functional groups on the surface of sunflower straw and the hard-to-remove cellulose remaining in the straw through its hydrolysis (Vladov et al. 2019). But when the impregnation ratio increased to 1:5, the C content of SSAC4 decreased (62.55\%), which might be caused by excessive $\mathrm{H}_{3} \mathrm{PO}_{4}$ attacking carbon materials.

The atomic ratio H/C can characterize the aromaticity of SSAC (Maroto-Valer et al. 1998), $\mathrm{O} / \mathrm{C}$ represents the surface hydrophilicity of SSAC (Chun et al. 2004), and $(\mathrm{O}+\mathrm{N}) / \mathrm{C}$ represents the polarity of SSAC (Chen et al. 2005). With the increase of impregnation ratio, the H/C values of the four kinds of SSAC changed slightly, but with a small range $(\leq 0.02)$, indicated that the change 
of aromaticity was not obvious. As the impregnation ratio increased from 1:1 to 1:3, the surface hydrophilicity and polarity of SSAC decrease. When the impregnation ratio increased to 1:5, the hydrophilicity and polarity of SSAC4 were greater than that of SSAC2 and less than that of SSAC1. Therefore, the increase of the impregnation ratio can affect the abundance of functional groups (decrease at 1:1 to 1:3, increase at 1:5), and the most abundant functional groups exist on the surface of SSAC1.

Table 1 Yield, elemental composition and atomic ratio of sunflower straw activated carbon

\begin{tabular}{ccccccccc}
\hline \multirow{2}{*}{ Samples } & \multirow{2}{*}{ Yield (\%) } & \multicolumn{2}{c}{ The mass fraction of $\mathrm{C}, \mathrm{N}, \mathrm{H}$ and $\mathrm{O}(\%)$} & \multicolumn{4}{c}{ Atomic ratio } \\
\cline { 3 - 9 } & & $\mathrm{C}$ & $\mathrm{H}$ & $\mathrm{N}$ & $\mathrm{O}$ & $\mathrm{H} / \mathrm{C}$ & $\mathrm{O} / \mathrm{C}$ & $(\mathrm{O}+\mathrm{N}) / \mathrm{C}$ \\
\hline SSAC1 & 38.00 & 60.33 & 1.38 & 0.14 & 38.15 & 0.27 & 0.47 & 0.48 \\
SSAC2 & 35.33 & 63.11 & 1.54 & 0.13 & 35.23 & 0.29 & 0.42 & 0.42 \\
SSAC3 & 36.00 & 67.34 & 1.54 & 0.39 & 30.73 & 0.27 & 0.34 & 0.35 \\
SSAC4 & 38.67 & 62.55 & 1.35 & 0 & 36.11 & 0.26 & 0.43 & 0.43 \\
\hline
\end{tabular}

\section{Scanning electron microscopy and characterization of pore structure}

Fig. 1 showed four types of SSAC scanning electron microscopes. SEM showed that when the immersion ratio is $1: 1$, dense circular holes with a diameter of 1-2 $\mu \mathrm{m}$ appear on the surface of SSAC1. When the impregnation ratio increased to $1: 2$, the number of pores on the surface of SSAC2 was greatly reduced, but the diameter of the pores that appeared increased to about $5 \mu \mathrm{m}$. As the impregnation ratio increased to $1: 3$ and 1:5, the pores changed from round to larger and narrow cracks $(>5 \mu \mathrm{m})$. At the same time, the increase in the impregnation ratio also makes the surface of SSAC rougher.

Fig. 2a showed the $\mathrm{N}_{2}$ adsorption-desorption isotherms of four SSAC. It could be seen from the figure that the four types of SSAC were basically in line with the characteristics of the type IV isotherm in the six physical adsorption isotherms divided by IUPAC (Sing et al. 1985), and the adsorption isotherm tended to the $\mathrm{Y}$ axis under lower pressure, showed it was the H4 hysteresis loop, which was the typical feature of the material containing both micropores and mesopores (Zhang et al. 2017). This could also be seen from the pore size distribution diagram in Fig. $2 b$.

The pore structure property data of SSAC was shown in Table 2. From the data in the table, it could be seen that the four types of SSAC prepared by using $\mathrm{H}_{3} \mathrm{PO}_{4}$ as the activator all had a large specific surface area $\left(S_{\mathrm{BET}}>1300 \mathrm{~m}^{2} \cdot \mathrm{g}^{-1}\right)$. As the impregnation ratio increased, the $S_{\mathrm{BET}}$ of SSAC also increases, and reached the maximum $\left(1794.01 \mathrm{~m}^{2} \cdot \mathrm{g}^{-1}\right)$ at 1:3. Among them, SSAC2 was about $20 \%$ larger than SSAC1, and SSAC3 was compared with SSAC2. The increase was small, about $5 \%$. However, when the impregnation ratio is increased to $1: 5$, the $S_{\mathrm{BET}}$ of SSAC4 is significantly reduced, slightly smaller than that of SSAC2, reaching $1643.21 \mathrm{~m}^{2} / \mathrm{g}$. This is due to the expansion of micropores due to the high impregnation ratio, which is caused by super-activation before the pore wall is destroyed (Hwang et al. 2008). As the impregnation ratio increased, the specific surface area $\left(S_{\mathrm{MI}}\right)$ of SSAC decreased and the specific surface area $\left(S_{\mathrm{EXT}}\right)$ increased. The total pore volume increased with the increase of the impregnation ratio, while the micropore volume decreased, on the contrary the mesopore volume increased. The formation of the pores of the material is due to the oxygen-containing functional groups in the sunflower straw reacting with the phosphoric acid vapor generated by the activator $\mathrm{H}_{3} \mathrm{PO}_{4}$ at high temperature and the $\mathrm{C}$ atoms in the straw to form pores (Zhang et al. 2017; Sun et al. 2015), $4 \mathrm{H}_{3} \mathrm{PO}_{4}+10 \mathrm{C} \rightarrow \mathrm{P}_{4}+10 \mathrm{CO}+6 \mathrm{H}_{2} \mathrm{O}$, $4 \mathrm{H}_{3} \mathrm{PO}_{4}+10 \mathrm{C} \rightarrow \mathrm{P}_{4} \mathrm{O}_{10}+6 \mathrm{H}_{2} \mathrm{O}, \mathrm{P}_{4} \mathrm{O}_{10}+10 \mathrm{C} \rightarrow \mathrm{P}_{4}+10 \mathrm{CO}$ (Myglovets et al. 2014). SSAC4 had the 
Table 2 Basic structural parameters of SSAC

\begin{tabular}{ccccccccc}
\hline Sample & $\begin{array}{c}S_{\mathrm{BET}^{\mathrm{a}}} \\
\left(\mathrm{m}^{2} / \mathrm{g}\right)\end{array}$ & $\begin{array}{c}S_{\mathrm{MI}^{\mathrm{b}}} \\
\left(\mathrm{m}^{2} / \mathrm{g}\right)\end{array}$ & $\begin{array}{c}S_{\mathrm{EXT}^{\mathrm{c}}} \\
\left(\mathrm{m}^{2} / \mathrm{g}\right)\end{array}$ & $\begin{array}{c}V_{\mathrm{t}}^{\mathrm{d}} \\
\left(\mathrm{cm}^{3} / \mathrm{g}\right)\end{array}$ & $\begin{array}{c}V_{\mathrm{MI}^{\mathrm{e}}} \\
\left(\mathrm{cm}^{3} / \mathrm{g}\right)\end{array}$ & $\begin{array}{c}V_{\mathrm{MES}^{\mathrm{f}}} \\
\left(\mathrm{cm}^{3} / \mathrm{g}\right)\end{array}$ & Microporosity $(\%)$ & $\begin{array}{c}\text { Average pore } \\
\text { size }(\mathrm{nm})\end{array}$ \\
\hline SSAC1 & 1357.86 & 871.85 & 486.01 & 0.761 & 0.383 & 0.378 & 50.33 & 2.29 \\
SSAC2 & 1702.03 & 628.32 & 1073.71 & 1.322 & 0.254 & 1.068 & 19.21 & 3.11 \\
SSAC3 & 1794.01 & 336.32 & 1457.69 & 2.023 & 0.123 & 1.900 & 6.08 & 4.51 \\
SSAC4 & 1643.21 & 172.13 & 1471.08 & 2.549 & 0.0527 & 2.496 & 2.07 & 6.21 \\
\hline
\end{tabular}

largest total pore volume $\left(2.549 \mathrm{~cm}^{3} / \mathrm{g}\right)$, the smallest microporosity $(2.07 \%)$, and an average pore diameter of $6.21 \mathrm{~nm}$, which was conducive to the entry of macromolecular substances such as dyes into the pores. In general, changing the amount of $\mathrm{H}_{3} \mathrm{PO}_{4}$ can change the surface and pore structure of sunflower straw activated carbon, but an excessively high impregnation ratio will lead to the collapse of micropores and decrease the specific surface area, while the increase in the $\mathrm{H}_{3} \mathrm{PO}_{4}$ impregnation ratio can promote mediation. The development of pores, SEM also confirmed this.
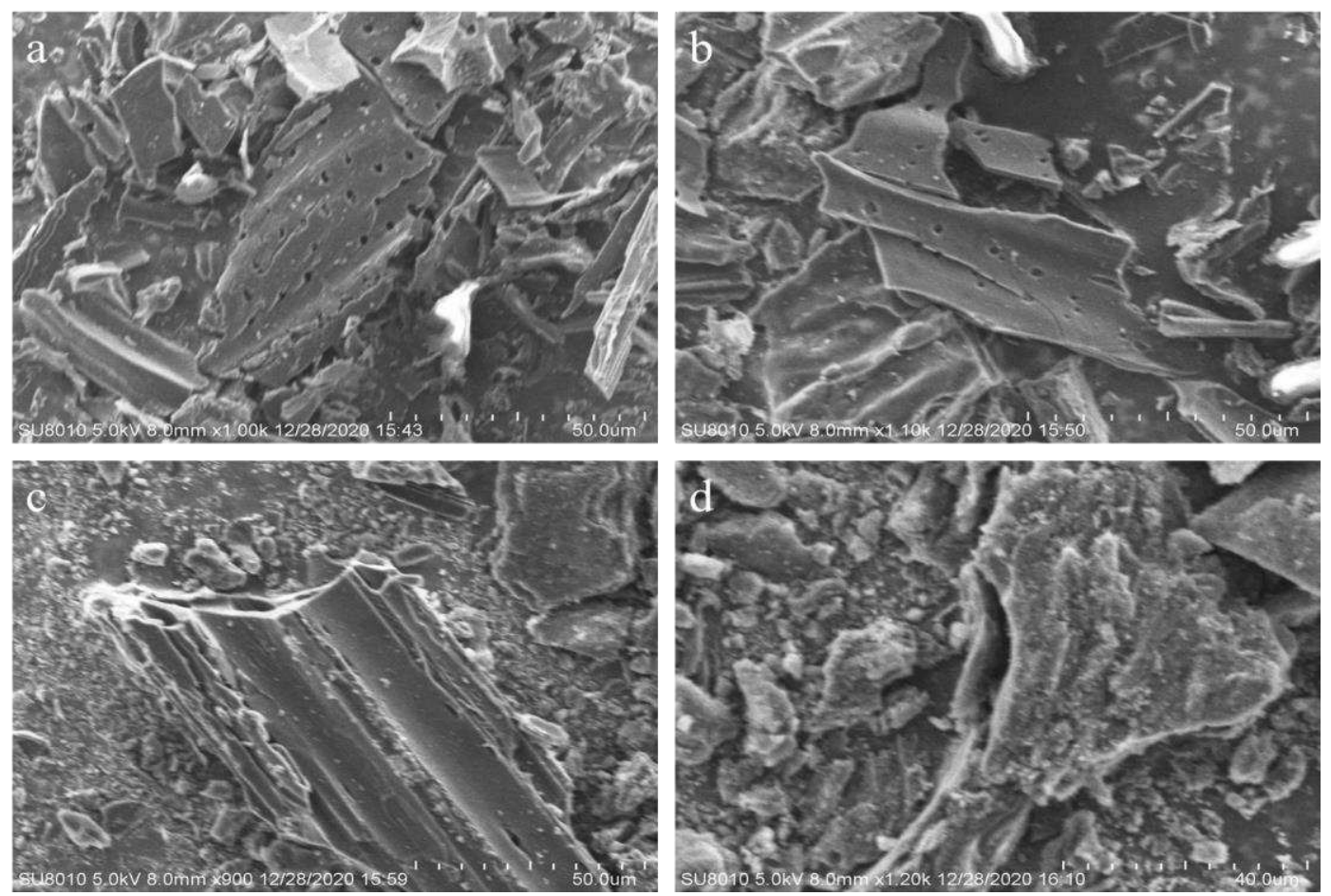

Fig. 1 SEM of SSAC1 (a), SSAC2 (b), SSAC3 (c) and SSAC4 (d)

a. Specific surface area, b. Micropore surface area from, c. External surface area, d. Total pore volume, e. Micropore volume, f. Mesopore volume 

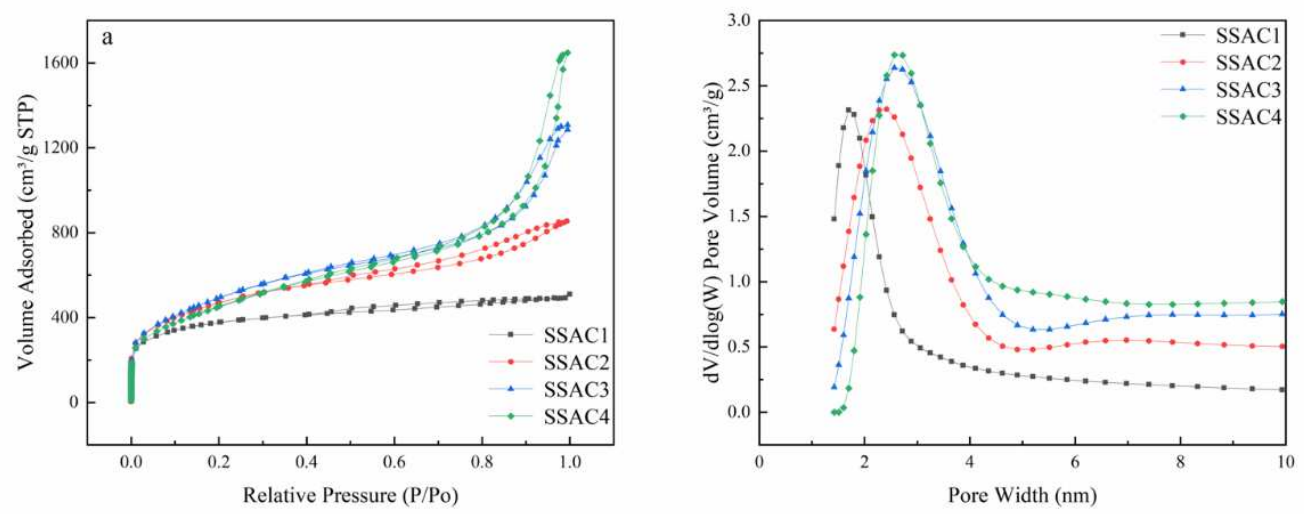

201

Fig. $2 \mathrm{~N}_{2}$ adsorption/desorption isotherm of SSAC (a); pore size distribution curve of SSAC (b)

\section{FT-IR of SSAC}

It could be seen from the Fig. 3 that the intensities of all peaks of SSAC2, SSAC3, and SSAC4 were significantly weaker than that of SSAC1, which was consistent with the elemental analysis results. Due to the stretching vibration of the O-H group, the characteristic peaks of the four types of SSAC appeared at $3448-3430 \mathrm{~cm}^{-1}$. At $2923 \mathrm{~cm}^{-1}$ was the characteristic peak produced by the stretching vibration of the C-H group. The characteristic peaks at $1635-1625 \mathrm{~cm}^{-1}$ and $1384 \mathrm{~cm}^{-1}$ were caused by the stretching vibration of $\mathrm{COO}^{-1}$ and $\mathrm{C}=\mathrm{O}$, but because SSAC was cleaned by $\mathrm{HCl}$, carboxylate and carbonyl ions were hydrolyzed by $\mathrm{HCl}$ to form aromatic rings, so the position at $1635-1625 \mathrm{~cm}^{-1}$ was caused by $\mathrm{C}=\mathrm{C}$ (Patidar and Vashishtha 2020). 1130-1126 $\mathrm{cm}^{-1}$ was the characteristic peak of $\mathrm{C}-\mathrm{O}-\mathrm{C}$ bond in plant cellulose. The peak at $599-570 \mathrm{~cm}^{-1}$ was caused by the vibration of the $\mathrm{C}-\mathrm{C}$ group.

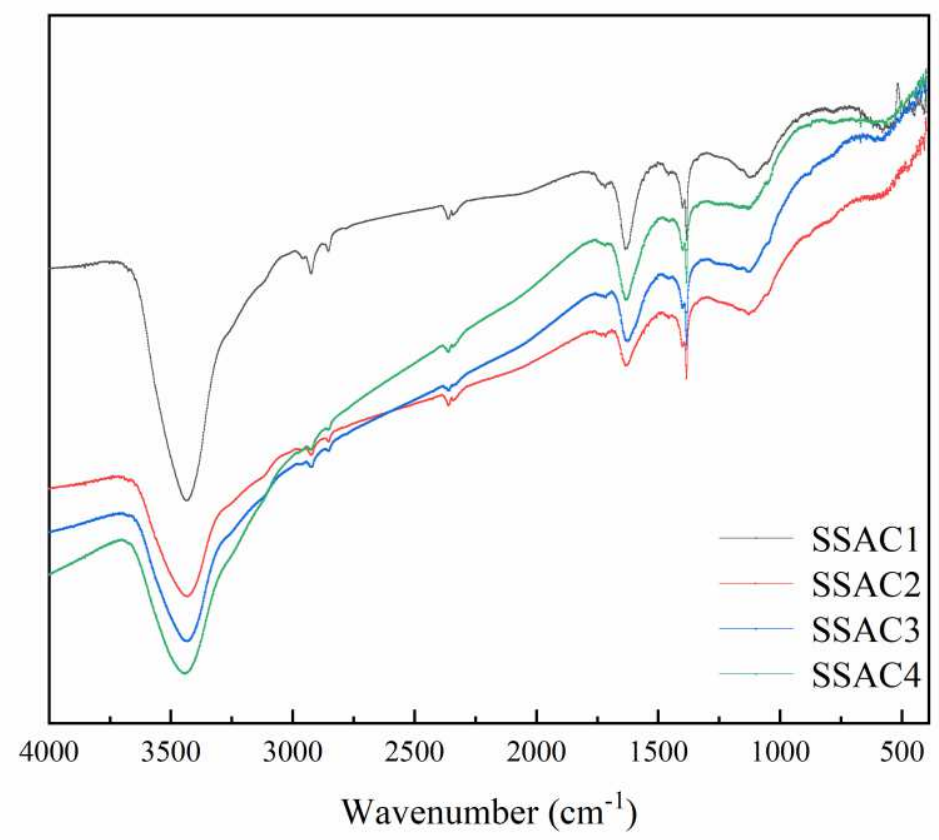

Fig. 3 FT-IR spectra of SSAC 
In order to investigate the adsorption effect of SSAC prepared under different immersion ratios on $\mathrm{AF}$ in water, the adsorption of four types of SSAC at a dosage of $1 \mathrm{~g} / \mathrm{L}$, a temperature of $303 \mathrm{~K}$ and an adsorption time of $4 \mathrm{~h}$ on the adsorption of $200 \mathrm{mg} / \mathrm{L}$ of AF was studied. Ability (expressed as removal rate $R \%$ ). The results were shown in Table 3. As the impregnation ratio increases, the removal rate of SSAC to AF also increased, and the removal rate of SSAC4 reached the maximum $(97.73 \%)$. According to the results of characterization analysis, SSAC1 had the most abundant surface functional groups, SSAC3 had the largest specific surface area, and SSAC4 had the smallest microporosity, largest and average pore size. Since the adsorption capacity was related to the pore volume and specific surface area, the removal effect was the best. The surface functional groups and specific surface area of SSAC4 were not the largest, so it could be considered that for SSAC, the pore size might be the main factor in determining the effect of removing AF. In order to further investigate the adsorption performance of SSAC to AF, four types of SSAC adsorption kinetic models and thermodynamic models of AF were studied below.

Table 3 The removal effect of SSAC with different immersion ratios on AF

\begin{tabular}{lll}
\hline Sample & $T(\mathrm{~K})$ & $R(\%)$ \\
\hline SSAC1 & & 67.58 \\
SSAC2 & 303 & 95.84 \\
SSAC3 & & 96.97 \\
SSAC4 & & 97.73 \\
\hline
\end{tabular}

\section{Effect of time and adsorption kinetics}

The pseudo-first-order kinetics (Eq.4) (Lagergren 1898), the pseudo-second-order kinetics (Eq.5) (Ho 2006) and the intra-particle diffusion model (Eq.6) (Tan et al. 2008) were used to evaluate the adsorption kinetics of AF by SSAC.

$$
q_{t}=q_{e}\left(1-\exp \left(-k_{1} t\right)\right)(4)
$$

$q_{t}=\frac{k_{2} q_{e}^{2} t}{1+k_{2} q_{e} t}(5)$

$$
q_{t}=k_{i} t^{\frac{1}{2}}+C_{i}(6)
$$

where, $q_{\mathrm{e}}(\mathrm{mg} / \mathrm{g})$ and $q_{\mathrm{t}}(\mathrm{mg} / \mathrm{g})$ are the adsorption capacity of SSAC on AF at adsorption equilibrium and $t(\mathrm{~min})$ time respectively; $k_{1}\left(\mathrm{~min}^{-1}\right), k_{2}(\mathrm{~g} /(\mathrm{mg} \cdot \mathrm{g}))$ and $k_{\mathrm{i}}\left(\mathrm{mg} /\left(\mathrm{g} \cdot \mathrm{min}^{1 / 2}\right)\right)$ are the adsorption rate constants, $C_{\mathrm{i}}$ is the constant related to the thickness of the boundary layer.

The adsorption kinetic curves of the four types of SSAC on AF are shown in Fig. 4a. SSAC1 and SSAC2 were both fast adsorption at 0-40 min, SSAC1 turned to slow adsorption at 40-140 min, then the adsorption of SSAC1 to AF basically reached equilibrium; while the slow adsorption of SSAC2 occurred at 40-120 min, and the adsorption was basically reached after 120 minutes balance. The fast adsorption stage of SSAC3 and SSAC4 was 0-15 min, and the slow adsorption stage was $15-80 \mathrm{~min}$. After $80 \mathrm{~min}$, the adsorption of SSAC3 and SSAC4 to AF basically reached equilibrium. Compared with the four types of SSAC, SSAC3 and SSAC4 took the shortest time to reach the slow adsorption and the final adsorption equilibrium. When the adsorption reached equilibrium, the saturated adsorption capacity of the four types of SSAC to AF was 


\section{SSAC4>SSAC3> SSAC2>SSAC1.}

The experimental data were fitted using the pseudo-first-order kinetic model, the pseudo-second-order kinetic model and the intra-particle diffusion model. The results are shown in Table 4 and Table 5. According to the kinetic parameters shown in Table 3, it can be seen that under the same concentration of $\mathrm{AF}$, the correlation coefficient $R^{2}$ of the pseudo-second-order kinetic models of the four kinds of SSAC models was all greater than 0.98 , while the correlation coefficient $R^{2}$ of the pseudo-first-order kinetic model was poor. Moreover, the calculated results of the pseudo-second-order kinetic model were closer to the experimental values, so it could be considered that the pseudo-second-order kinetic model was more suitable to explain the adsorption kinetic model of SSAC on AF, so the adsorption process of SSAC on AF included chemical adsorption (Liu et al. 2017).

Intra-particle diffusion model was used to further investigate the adsorption mechanism of SSAC on AF. It can be seen from Fig. 4b that the process of the four kinds of SSAC on AF is presented in three stages, indicating that the adsorption process is composed of multiple steps. It can be seen from the data in Table 5 that the correlation coefficient $R^{2}$ of the three processes in the intra particle diffusion model was all above 0.86 , and all the $C_{\mathrm{i}}$ values were not 0 , so it could be concluded that intra particle diffusion was involved in the adsorption process, but it was not the only control step (Wu et al. 2014). $k_{\mathrm{i}}$ values of the three stages of the four ACs decreased successively $\left(k_{\mathrm{i} 1}>k_{\mathrm{i} 2}>k_{\mathrm{i} 3}\right)$, indicating that in the first stage, AF molecules controlled by molecular diffusion and membrane diffusion were transferred from the solution to the surface of SSAC; in the second stage, AF molecules were transferred from the surface of SSAC to the pore; this process was intra-particle diffusion; in the third stage, adsorption reached equilibrium (Zeng et al. 2019). It can be concluded that the diffusion rate of AF was limited by both membrane diffusion and intra-particle diffusion.

Table 4 Pseudo-first-order and pseudo-second-order kinetic model parameters of the adsorption of AF by SSAC

\begin{tabular}{lccccccc}
\hline & & \multicolumn{3}{c}{ Pseudo-first-order kinetic model } & \multicolumn{2}{c}{ Pseudo-second-order kinetic model } \\
\cline { 3 - 8 } Sample & $q_{\mathrm{e}, \exp }(\mathrm{mg} / \mathrm{g})$ & $q_{\mathrm{e}, \text { cal }}(\mathrm{mg} / \mathrm{g})$ & $k_{1}\left(\mathrm{~min}^{-1}\right)$ & $R^{2}$ & $q_{\mathrm{e}, \text { cal }}(\mathrm{mg} / \mathrm{g})$ & $\begin{array}{c}k_{2} \times 10^{-2} \\
(\mathrm{~g} /(\mathrm{mg} \cdot \mathrm{g}))\end{array}$ & $R^{2}$ \\
\hline SSAC1 & 135.16 & 195.77 & 0.0678 & 0.94253 & 142.37 & 0.0676 & 0.99303 \\
SSAC2 & 191.68 & 187.05 & 0.162 & 0.89039 & 194.88 & 0.156 & 0.99926 \\
SSAC3 & 193.94 & 191.54 & 0.420 & 0.79541 & 194.28 & 0.739 & 0.99092 \\
SSAC4 & 195.46 & 194.18 & 0.541 & 0.77343 & 195.77 & 1.369 & 0.98549 \\
\hline
\end{tabular}

Table 5 Intra-particle diffusion model parameters of SSAC versus AF adsorption

\begin{tabular}{lcccccccccc}
\hline & \multicolumn{3}{c}{ The first stage } & \multicolumn{3}{c}{ The second stage } & \multicolumn{3}{c}{ The third stage } \\
\cline { 2 - 12 } Sample & $k_{\mathrm{i} 1}$ & $C_{\mathrm{i} 1}$ & $R^{2}$ & $\begin{array}{c}k_{\mathrm{i} 2} \\
\left(\mathrm{mg} /\left(\mathrm{g} \cdot \mathrm{min}^{1 / 2}\right)\right)\end{array}$ & $C_{\mathrm{i} 2}$ & $R^{2}$ & $k_{\mathrm{i} 3}$ \\
& $\left(\mathrm{mg} /\left(\mathrm{g} \cdot \mathrm{min}^{1 / 2}\right)\right)$
\end{tabular}



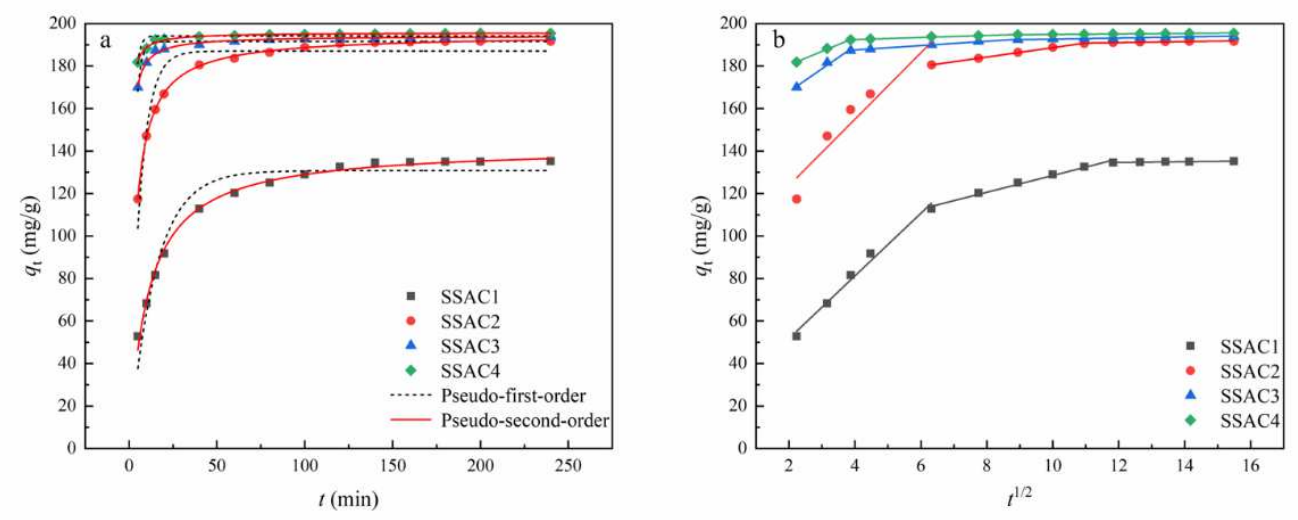

277

278

Fig. 4 Fitting of pseudo-first-order and pseudo-second-order kinetic models of AF adsorption by SSAC (a); intra-particle diffusion model (b)

\section{Adsorption isothermal}

In order to study the adsorption behavior of SSAC to AF, this paper uses Langmuir (Eq. 7) (Langmuir 1918), Freundlich (Eq. 8) (Freundlich 1906) and Temkin (Eq. 9) (Temkin and Pyzhev 1940) adsorption isotherm models at three temperatures $(293 \mathrm{~K}, 298 \mathrm{~K}, 303 \mathrm{~K})$ for non-linear fitting of experimental data.

$q_{e}=\frac{q_{m} k_{L} C_{e}}{1+k_{L} C_{e}}(7)$

$q_{e}=k_{F} C_{e}^{1 / n}(8)$

$q_{e}=k_{T} \ln B_{T}+k_{F} \ln C_{e}(9)$

where $C_{e}(\mathrm{mg} / \mathrm{L})$ is the concentration of $\mathrm{AF}$ in adsorption equilibrium, $q_{e}(\mathrm{mg} / \mathrm{g})$ is the adsorption capacity of SSAC to AF in adsorption equilibrium, $1 / n$ is the heterogeneous factor, $B_{\mathrm{T}}(\mathrm{L} / \mathrm{min})$ is the equilibrium binding constant, $k_{L}(\mathrm{~L} / \mathrm{mg}), k_{F}\left((\mathrm{mg} / \mathrm{g}) \cdot(\mathrm{L} / \mathrm{mg})^{1 / \mathrm{n}}\right)$.

The adsorption isotherms of four types of SSAC to AF are shown in Fig. 5, and the fitting data are shown in Table 6. It can be seen from the adsorption isotherm that as the SSAC immersion ratio increases, the equilibrium adsorption capacity of the four SSAC for AF also increases, and the equilibrium concentration of AF in the solution decreases, and the immersion ratio increases from 1:1 When it reached 1:3, the equilibrium adsorption capacity increases more obviously, while the impregnation ratio was expanded from 1:3 to 1:5, and the equilibrium adsorption capacity increases slightly. This may be because the increase in the AF concentration provides more for the adsorption process. Driving force to control the resistance of AF transfer from liquid to solid (Qiao et al. 2016; Yang et al. 2020).

From the data in Table 6, for SSAC3 and SSAC4, the Langmuir adsorption isotherm model fits better, indicating that the adsorption of these two types of SSAC were more inclined to monolayer adsorption and chemical adsorption, and $0<k_{L}<1$, indicating this was a favorable adsorption process (Foo and Hameed 2010).

For SSAC1 and SSAC2, the correlation coefficient $R^{2}$ obtained from the Freundlich adsorption isotherm model were the highest, indicating that the two types of SSAC were non-uniform surfaces, adsorbed as multi-molecular layers, and had adsorption behavior of physical adsorption. The heterogeneity factor $1 / n<1$ indicated that Easy to adsorb and the 
adsorption process was favorable (Adamson and Gast 1997).

Since the Temkin adsorption isotherm model fits the four types of SSAC well $\left(R^{2}>0.96\right)$, it indicated that there was chemical adsorption. In summary, the three adsorption models of Langmuir, Freundlich and Temkin had high correlation coefficients for the four types of SSAC $\left(R^{2}>0.96\right)$. It can be considered that the adsorption behavior of AF on the SSAC surface includes both physical and chemical adsorption.

According to the fitting data, at $303 \mathrm{~K}$, the maximum adsorption capacity of the four types of SSAC for AF were greater than $600 \mathrm{mg} / \mathrm{g}$, of which SSAC4 had the highest maximum adsorption capacity for AF, which was $2763.36 \mathrm{mg} / \mathrm{g}$. Table 7 compared the adsorption of different materials to AF. The data showed that compared with other materials, the four types of SSAC all exhibit better adsorption performance to AF. Therefore, SSAC has great potential for the adsorption of AF.

Table 6 Thermodynamic model of adsorption of AF by AC

\begin{tabular}{|c|c|c|c|c|c|c|c|c|c|c|}
\hline \multirow[b]{2}{*}{ Sample } & \multirow[b]{2}{*}{$T(\mathrm{~K})$} & \multicolumn{3}{|c|}{ Langmuir } & \multicolumn{3}{|c|}{ Freundlich } & \multicolumn{3}{|c|}{ Temkin } \\
\hline & & $\begin{array}{l}k \mathrm{~L} \times 10^{-2} \\
(\mathrm{~L} / \mathrm{mg})\end{array}$ & $q_{\mathrm{m}}(\mathrm{mg} / \mathrm{g})$ & $R^{2}$ & $\begin{array}{l}k_{\mathrm{F}}((\mathrm{mg} / \mathrm{g}) \\
\left.(\mathrm{L} / \mathrm{mg})^{1 / \mathrm{n}}\right)\end{array}$ & $1 / n$ & $R^{2}$ & $k_{\mathrm{T}}(\mathrm{L} / \mathrm{mg})$ & $B_{\mathrm{T}}$ & $R^{2}$ \\
\hline \multirow{3}{*}{ SSAC1 } & 293 & 0.247 & 538.71 & 0.98046 & 9.174 & 0.558 & 0.99107 & 117.540 & 0.0245 & 0.97051 \\
\hline & 298 & 0.298 & 564.90 & 0.97637 & 12.418 & 0.531 & 0.99283 & 121.974 & 0.0307 & 0.96302 \\
\hline & 303 & 0.372 & 602.34 & 0.98361 & 16.839 & 0.508 & 0.99509 & 132.826 & 0.0368 & 0.97605 \\
\hline \multirow{3}{*}{ SSAC2 } & 293 & 1.303 & 913.491 & 0.98614 & 60.602 & 0.451 & 0.99104 & 199.371 & 0.133 & 0.98958 \\
\hline & 298 & 1.732 & 935.72 & 0.97251 & 72.595 & 0.443 & 0.99279 & 200.129 & 0.186 & 0.98058 \\
\hline & 303 & 2.494 & 965.527 & 0.97092 & 91.373 & 0.431 & 0.99148 & 205.342 & 0.271 & 0.98106 \\
\hline \multirow{3}{*}{ SSAC3 } & 293 & 1.037 & 2521.25 & 0.99906 & 43.932 & 0.761 & 0.99664 & 386.090 & 0.172 & 0.97093 \\
\hline & 298 & 1.229 & 2590.13 & 0.99794 & 50.638 & 0.765 & 0.99134 & 403.574 & 0.197 & 0.97641 \\
\hline & 303 & 1.385 & 2718.07 & 0.99614 & 56.545 & 0.775 & 0.98757 & 417.022 & 0.225 & 0.97709 \\
\hline \multirow{3}{*}{ SSAC4 } & 293 & 1.205 & 2531.81 & 0.99922 & 49.817 & 0.759 & 0.99719 & 382.819 & 0.205 & 0.96454 \\
\hline & 298 & 1.506 & 2679.70 & 0.99816 & 60.164 & 0.771 & 0.99235 & 407.521 & 0.249 & 0.97382 \\
\hline & 303 & 1.829 & 2763.36 & 0.9966 & 70.927 & 0.777 & 0.98887 & 420.469 & 0.300 & 0.97678 \\
\hline
\end{tabular}



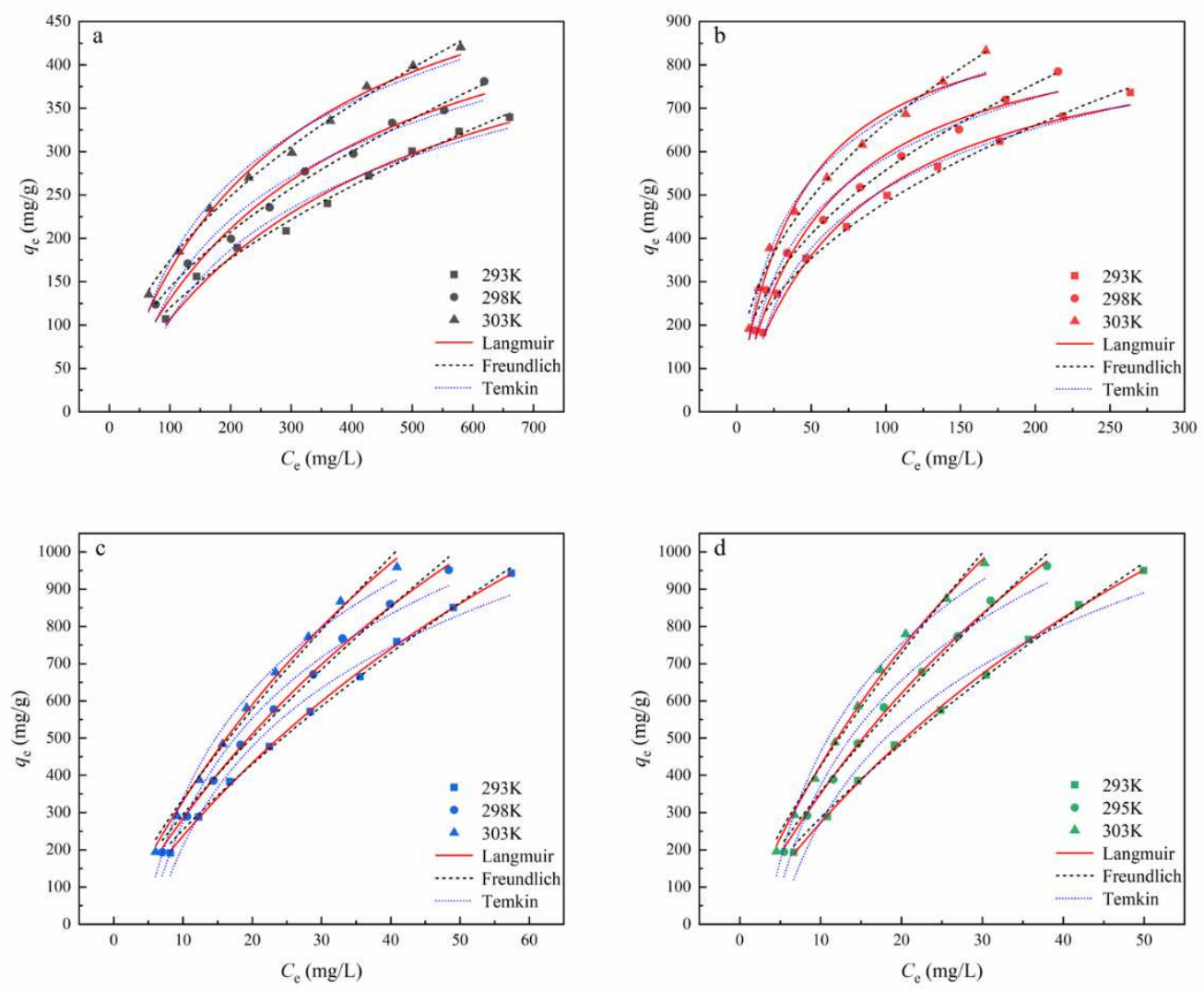

322 Fig. 5 Fitting curve of adsorption isotherm for SSAC1(a), SSAC2(b), SSAC3(c) and SSAC4(d)

323 adsorption of $\mathrm{AF}$

324 Table 7 Comparison of the adsorption capacity of different adsorbents for AF

\begin{tabular}{|c|c|c|c|c|c|c|}
\hline Adsorbents & Material composition & $\begin{array}{c}S_{\text {BET }} \\
\left(\mathrm{m}^{2} / \mathrm{g}\right)\end{array}$ & $\begin{array}{l}\text { pore volume } \\
\left(\mathrm{cm}^{3} / \mathrm{g}\right)\end{array}$ & $T(\mathrm{~K})$ & $q_{\max }(\mathrm{mg} / \mathrm{g})$ & References \\
\hline $\mathrm{CAC}$ & $\begin{array}{l}\text { Commercial granular activated } \\
\text { carbon } / \mathrm{Al}_{2} \mathrm{O}_{3}\end{array}$ & 294.1 & 0.2643 & 308 & 181.82 & $\begin{array}{c}\text { (Dutta and Basu } \\
\text { 2014) }\end{array}$ \\
\hline $\mathrm{BC}-\mathrm{Cu} / \mathrm{Si}-\mathrm{NH}_{2}$ & $\begin{array}{c}\text { bamboo charcoal } / \mathrm{CuSO}_{4} \cdot 5 \mathrm{H}_{2} \mathrm{O} / \\
\qquad \mathrm{Si}-\mathrm{NH}_{2}\end{array}$ & l & I & 313 & 10.77 & $\begin{array}{l}\text { (Zhang et al. } \\
\text { 2019) }\end{array}$ \\
\hline $\begin{array}{l}\text { De-oiled } \\
\text { biomass }\end{array}$ & Sargassum myriocystum & 2.1197 & 0.1318 & 308 & 9.9 & $\begin{array}{c}\text { (Renita et al. } \\
\text { 2019) }\end{array}$ \\
\hline $\mathrm{MB}, \mathrm{MG}$ & $\begin{array}{c}\text { Elm branches, turfgrass/ sodium } \\
\text { citrate }\end{array}$ & l & l & 313 & $142.91 \sim 182.21$ & (Ma et al. 2020) \\
\hline $\mathrm{MnO}_{2} / \mathrm{MCM}-41$ & $\mathrm{MCM}-41 / \mathrm{MnO}_{2}$ & l & l & 318 & 1022.055 & $\begin{array}{l}\text { (Yang et al. } \\
\text { 2015b) }\end{array}$ \\
\hline SBPF & $\mathrm{Sr}_{5 \mathrm{x}} \mathrm{Ba}_{3 \mathrm{x}}\left(\mathrm{PO}_{4}\right)_{3}(\mathrm{OH}) / \mathrm{Fe}_{3} \mathrm{O}_{4}$ & 45.3 & l & 328 & 1590 & (Yin et al. 2015) \\
\hline CSAF & magnetic Chitosan $/ \mathrm{Al}_{2} \mathrm{O}_{3} / \mathrm{Fe}_{3} \mathrm{O}_{4}$ & 33.69 & 0.095 & 308 & 1666.67 & $\begin{array}{c}\text { (Akbarnejad et al. } \\
\text { 2019) }\end{array}$ \\
\hline LMZ & Laccase-Modified Zeolite & 40.80 & l & 333 & 332 & $\begin{array}{c}\text { (Kalkan et al. } \\
\text { 2015) }\end{array}$ \\
\hline SSAC1 & Sunflower straw & 486.01 & 0.761 & 303 & 602.34 & This work \\
\hline
\end{tabular}




\begin{tabular}{lllc}
\hline SSAC2 & 1073.71 & 1.322 & 965.52 \\
SSAC3 & 1457.69 & 2.023 & 2718.07 \\
SSAC4 & 1471.08 & 2.549 & 2763.36 \\
\hline
\end{tabular}

\section{Thermodynamic studies}

326 In order to understand the effect of temperature to SSAC adsorption AF, we examined changes in 327 thermodynamic parameters at temperatures 293 to $303 \mathrm{~K}$, including: Gibbs Free Energy $(\Delta G)$ Eq. 328 11, enthalpy $(\Delta H)$ Eq. 12 and Entropy $(\Delta S)$ Eq. 12 (Yang et al. 2020; Ai et al. 2011), the formula is 329 as follows: $K_{d}=\frac{q_{e}}{C_{e}}(10)$ $\Delta G=\Delta H-T \Delta S(12)$ where $K_{\mathrm{d}}$ is a distribution coefficient, $R$ is the gas constant in an ideal state $(8.314 \mathrm{~J} /(\mathrm{mol} \cdot \mathrm{K})), T$ is absolute temperature $(\mathrm{K}), \Delta G$ is Gibbs free energy change $(\mathrm{kJ} / \mathrm{mol}), \Delta \mathrm{H}(\mathrm{kJ} / \mathrm{mol})$ is a reactive enthalpy, $\Delta S(\mathrm{~kJ} /(\mathrm{K} \cdot \mathrm{mol}))$ is the entropy change of the reaction. It can be seen from Table 8 that the $\Delta G$ of the four SSAC were negative, and the absolute value of $\Delta G$ increased as the experimental temperature increased, indicated that the adsorption of the SSAC to AF was spontaneously and absorbed. At the same time, the value of $\Delta G$ was between -20 to 0 , indicated that the adsorption properties had physical adsorption (Jaycock and Parfitt 1981), and the high $R^{2}$ value of the Freundlich isometric confirmed this. The value of $\Delta H$ was greater than 0 , further confirming that the adsorption was the heat absorbing process (Mahmoodi et al. 2010). $\Delta S$ was a positive value indicated that the randomness of the solid-solute interface during the adsorption of

343 AF was increased (El-Bindary et al. 2014).

Table 8 Thermodynamic parameters of SSAC adsorb AF

\begin{tabular}{cccccc}
\hline Sample & $T(\mathrm{~K})$ & $K_{\mathrm{d}}$ & $\Delta G(\mathrm{~kJ} / \mathrm{mol})$ & $\Delta H(\mathrm{~kJ} / \mathrm{mol})$ & $\Delta S(\mathrm{~kJ} /(\mathrm{mol} \cdot \mathrm{K}))$ \\
\hline \multirow{3}{*}{ SSAC1 } & 293 & 1.15 & -0.35 & & \\
& 298 & 1.62 & -1.20 & 43.68 & 0.15 \\
& 303 & 2.08 & -1.85 & & \\
SSAC2 & 293 & 10.31 & -5.68 & & \\
& 298 & 14.86 & -6.68 & 59.28 & \\
\hline \multirow{3}{*}{ SSAC3 } & 303 & 23.03 & -7.90 & & 0.10 \\
& 293 & 23.49 & -7.69 & & \\
& 298 & 27.47 & -8.21 & & \\
& 303 & 32.01 & -8.93 & & \\
SSAC4 & 293 & 28.95 & -8.20 & & \\
& 298 & 35.43 & -8.84 & 29.25 & \\
\hline
\end{tabular}

\section{Conclusion}

346 In this experiment, $\mathrm{H}_{3} \mathrm{PO}_{4}$ was used as the activator, and the sunflower straw activated carbon was successfully prepared using the one-step activation method under the preparation conditions of 
$600{ }^{\circ} \mathrm{C}$. It can be seen from the characterization results that the impregnation ratio has a great influence on the performance of SSAC. When the impregnation ratio increased within a certain range, the specific surface area of SSAC would increase, and it reached the maximum when the impregnation ratio was $1: 3\left(1794.01 \mathrm{~m}^{2} \cdot \mathrm{g}^{-1}\right)$, but when the impregnation ratio increased to $1: 5$, the specific surface area would decrease $\left(1643.21 \mathrm{~m}^{2} \cdot \mathrm{g}^{-1}\right)$ due to the collapse of micropores caused by hyper-activation. At the same time, the microporosity rate was also reduced from $50.33 \%$ at $1: 1$ to $2.07 \%$ at $1: 5$. It showed that the SSAC prepared by using $\mathrm{H}_{3} \mathrm{PO}_{4}$ to activate sunflower straw was mainly mesoporous. SSAC prepared with different impregnation ratios all showed higher adsorption capacity for AF. The quasi-second-order kinetic model was suitable for describing the adsorption kinetics of the four types of SSAC. The Langmuir adsorption isotherm model was suitable for describing the adsorption process of SSAC1, SSAC3 and SSAC4, while SSAC2 was more in line with the Freundlich model. Generally, the three adsorption isotherm models of Langmuir, Freundlich and Temkin have good correlation coefficients. The adsorption of AF on the four types of SSAC was a process of spontaneous heat absorption, so the adsorption of SSAC to AF had two effects: physical adsorption and chemical adsorption. Among the four types of SSAC, SSAC4 had not the largest specific surface area, but had the lowest microporosity $(2.07 \%)$, the largest total pore volume $\left(2.549 \mathrm{~cm}^{3} \cdot \mathrm{g}^{-1}\right)$ and average pore size $(6.21 \mathrm{~nm})$. SSAC4 had the best removal effect on AF dye wastewater. Under the condition of $303 \mathrm{~K}$, the removal rate of $200 \mathrm{mg} / \mathrm{L}$ AF wastewater was $97.73 \%$, and its maximum adsorption capacity for AF was $2763.36 \mathrm{mg} / \mathrm{g}$, which was the highest among the four types of SSAC. Therefore, SSAC4 prepared with an immersion ratio of $1: 5$ at $600{ }^{\circ} \mathrm{C}$ was a potential SSAC material for removing AF in water. SSAC had simple preparation method and low cost, realizes the secondary utilization of agricultural waste, and achieves the purpose of treating waste with waste.

Funding This work was supported in part by the Major Science and Technology Project in Inner Mongolia Autonomous Region (2019ZD002).

Availability of data and materials The datasets used and/or analyzed during the current study are available from the corresponding author on reasonable request.

Competing interests The authors declare that they have no competing interests

Authors' contributions Material preparation, data collection and analysis, the first draft of the manuscript was written by Wende Zhao.

Liping Chen: Conceptualization, funding acquisition, writing-review and editing and supervision.

\section{Ethics approval and consent to participate Not applicable}

Consent for publication Not applicable

\section{Reference}

Adamson AW, Gast AP (1997) Physical Chemistry of Surfaces, sixth ed. Wiley Interscience, New York.

Ahmed MJ (2016) Application of agriculturally based activated carbons by microwave and conventional activations for basic dye adsorption: Review. J Environ Chem Eng 4(1):89-99. https://doi.org/10.1016/j.jece.2015.10.027 
Ahmed MJ (2017) Adsorption of quinolone, tetracycline, and penicillin antibiotics from aqueous solution using activated carbons: Review. Environ Toxicol Pharmacol 50:1-10. https://doi.org/10.1016/j.etap.2017.01.004 Ai L, Li M, Li L (2011) Adsorption of Methylene Blue from Aqueous Solution with Activated Carbon/Cobalt Ferrite/Alginate Composite Beads: Kinetics, Isotherms, and Thermodynamics. J Chem Eng Data 56(8):3475-3483. https://doi.org/10.1021/je200536h

Akbarnejad S, Amooey AA, Ghasemi S (2019) High effective adsorption of acid fuchsin dye using magnetic biodegradable polymer-based nanocomposite from aqueous solutions. Microchem J 149:103966. https://doi.org/10.1016/j.microc.2019.103966

Baba M, Schols D, Pauwels R, Balzarini J, Clercq ED (1998) Fuchsin acid selectively inhibits human immunodeficiency virus (HIV) replication in vitro. Biochem Biophys Res Commun 155(3):1404-1411. https://doi.org/10.1016/S0006-291X(88)81297-X

Bastidas JM, Pinilla P, Cano E, Polo JL, Miguel S (2003) Copper corrosion inhibition by triphenylmethane derivatives in sulphuric acid media. Corros Sci 45(2):427-449. https://doi.org/10.1016/S0010-938X(02)00123-3

Burke V, Skinner CE (1924) The reverse selective bacteriostatic action of acid fuchsin. J Exp Med 39(4):613-624. https://doi.org/10.1084/jem.39.4.613

Chen BL, Johnson EJ, Chefetz B, Zhu LZ, Xing BS (2005) Sorption of polar and nonpolar aromatic organic contaminants by plant cuticular materials: Role of polarity and accessibility. Environ Sci Technol 39(16):6138-6146. https://doi.org/10.1021/es050622q

Chun Y, Sheng GY, Chiou CT, Xing BS (2004) Compositions and sorptive properties of crop residue-derived chars. Environ Sci Technol 38(17):4649-4655. https://doi.org/10.1021/es035034w

Dutta M, Basu JK (2014) Fixed-bed column study for the adsorptive removal of acid fuchsin using carbon-alumina composite pellet. Int J Environ Sci Technol 11(1):87-96. https://doi.org/10.1007/s13762-013-0386-X

El-Bindary AA, Hussien MA, Diab MA, Eessa AM (2014) Adsorption of Acid Yellow 99 by polyacrylonitrile/activated carbon composite: Kinetics, thermodynamics and isotherm studies. J Mol Liq 197:236-242. https://doi.org/10.1016/j.molliq.2014.05.003

Foo KY, Hameed BH (2010) Insights into the modeling of adsorption isotherm systems. Chem Eng J 159(1):2-10. https://doi.org/10.1016/j.cej.2009.09.013

Freundlich, H.M (1906) Over the adsorption in solution. J Phys Chem. 57:385-470.

Gao Z, Yi Y, Zhao J, Xia Y, Jiang M, Cao F, et al (2018) Co-immobilization of laccase and TEMPO onto amino-functionalized magnetic $\mathrm{Fe} 3 \mathrm{O} 4$ nanoparticles and its application in acid fuchsin decolorization. Bioresources and Bioprocessing 5:27. https://doi.org/10.1186/s40643-018-0215-7

Greer, L., Keane, S., Lin, C., Zhou, A., Yiliqi, Tong, T (2015) The textile industry leaps forward with clean by design: less environmental impact with bigger profits. Natural Resources Defense Council.

Ho YS (2006) Review of second-order models for adsorption systems. J Hazard Mater 136(3):681-689. https://doi.org/10.1016/j.jhazmat.2005.12.043

Hwang HR, Choi WJ, Kim TJ, Kim JS, Oh KJ (2008) The preparation of an adsorbent from mixtures of sewage sludge and coal-tar pitch using an alkaline hydroxide activation agent. J Anal Appl Pyrolysis 83(2):220-226. https://doi.org/10.1016/j.jaap.2008.09.011

Jaycock MJ, Parfitt GD (1981) Chemistry of Interfaces. Onichester, Ellis Horwood Ltd

Kalkan E, Nadaroglu H, Celebi N, Celik H, Tasgin E (2015) Experimental Study to Remediate Acid Fuchsin Dye Using Laccase-Modified Zeolite from Aqueous Solutions. Pol J Environ Stud 24(1):115-124. https://doi.org/10.15244/pjoes/23797

Kong J, Huang L, Yue Q, Gao B (2014) Preparation of activated carbon derived from leather waste by H3PO4 
activation and its application for basic fuchsin adsorption. Desalin Water Treat 52(13-15):2440-2449. https://doi.org/10.1080/19443994.2013.794713

Lagergren, S (1898) About the theory of so-called adsorption of soluble substances. K Sven Vetenskapsakad Handl. 24(4):1-39.

Langmuir, I (1918) The adsorption of gases on plane surface of glasses. J Am Chem Soc 40:1361-1403.

Liu S, Xu W-h, Liu Y-g, Tan X-f, Zeng G-m, Li X, et al (2017) Facile synthesis of Cu (II) impregnated biochar with enhanced adsorption activity for the removal of doxycycline hydrochloride from water. Sci Total Environ 592:546-553. https://doi.org/10.1016/j.scitotenv.2017.03.087

Liu YQ, Maulidiany N, Zeng P, Heo S (2021) Decolourization of azo, anthraquinone and triphenylmethane dyes using aerobic granules: Acclimatization and long-term stability. Chemosphere 263:128312. https://doi.org/10.1016/j.chemosphere.2020.128312

Ma H, Feng L, Kang M, Yang Z, Zhang R, Li H, et al (2020) Potential Low-Cost Biosorbent Modified from Yard Waste for Acid-Fuchsin Removal. J Environ Eng 146(8):04020085. https://doi.org/10.1061/(ASCE)EE.1943-7870.0001757

Mahmoodi NM, Arami M, Bahrami H, Khorramfar S (2010) Novel biosorbent (Canola hull): Surface characterization and dye removal ability at different cationic dye concentrations. Desalination 264(1-2):134-142. https://doi.org/10.1016/j.desal.2010.07.017

Maroto-Valer MM, Andresen JM, Snape CE (1998) Verification of the linear relationship between carbon aromaticities and $\mathrm{H} / \mathrm{C}$ ratios for bituminous coals. Fuel 77(7):783-785. https://doi.org/10.1016/S0016-2361(97)00227-5

Myglovets M, Poddubnaya OI, Sevastyanova O, Lindstrom ME, Gawdzik B, Sobiesiak M, et al (2014) Preparation of carbon adsorbents from lignosulfonate by phosphoric acid activation for the adsorption of metal ions. Carbon 80:771-783. https://doi.org/10.1016/j.carbon.2014.09.032

Patidar K, Vashishtha M (2020) Optimization of Process Variables to Prepare Mesoporous Activated Carbon from Mustard Straw for Dye Adsorption Using Response Surface Methodology. Water Air Soil Pollut 231(10):526. https://doi.org/10.1007/s11270-020-04893-4

Peiris C, Gunatilake SR, Mlsna TE, Mohan D, Vithanage M (2017) Biochar based removal of antibiotic sulfonamides and tetracyclines in aquatic environments: A critical review. Bioresour Technol 246:150-159. https://doi.org/10.1016/j.biortech.2017.07.150

Putra EK, Pranowo R, Sunarso J, Indraswati N, Ismadji S (2009) Performance of activated carbon and bentonite for adsorption of amoxicillin from wastewater: Mechanisms, isotherms and kinetics. Water Res 43(9):2419-2430. https://doi.org/10.1016/j.watres.2009.02.039

Qiao XQ, Hu FC, Tian FY, Hou DF, Li DS (2016) Equilibrium and kinetic studies on MB adsorption by ultrathin 2D MoS2 nanosheets. Rsc Adv 6(14):11631-11636. https://doi.org/10.1039/c5ra24328a

Radjenovic J, Sedlak DL (2015) Challenges and opportunities for electrochemical processes as next-generation technologies for the treatment of contaminated water. Environ Sci Technol 49:11292-11302. https://doi.org/10.1021/acs.est.5b02414

Rahnama S, Shariati S, Divsar F (2018) Synthesis of Functionalized Magnetite Titanium Dioxide Nanocomposite for Removal of Acid Fuchsine Dye. Comb Chem High Throughput Screening 21(8):583-593. https://doi.org/10.2174/1386207321666181019111211

Reffas A, Bernardet V, David B, Reinert L, Lehocine MB, Dubois M, et al (2010) Carbons prepared from coffee grounds by H3PO4 activation: Characterization and adsorption of methylene blue and Nylosan Red N-2RBL. J Hazard Mater 175(1-3):779-788. https://doi.org/10.1016/j.jhazmat.2009.10.076

Renita AA, Kumar PS, Jabasingh SA (2019) Redemption of acid fuchsin dye from wastewater using de-oiled 
biomass: Kinetics and isotherm analysis. Bioresource Technology Reports 7:100300.

https://doi.org/10.1016/j.biteb.2019.100300

Sheng Y, Zhen L, Wang X, Li N, Tong Q (2010) Degradation of acid fuchsine by a modified electro-Fenton system with magnetic stirring as oxygen supplying. J Environ Sci 22(4):547-54. https://doi.org/10.1016/S1001-0742(09)60144-3

Sing KSW, Everett DH, Haul RAW, Moscou L, Pierotti RA, Rouquerol J, et al (1985) Reporting Physisorption Data for Gas Solid Systems with Special Reference to the Determination of Surface Area and Porosit. Pure Appl Chem 57(4):603-619. https://doi.org/10.1351/pac198557040603

Song M, Zhang W, Chen Y, Luo J, Crittenden JC (2017) The preparation and performance of lignin-based activated carbon fiber adsorbents for treating gaseous streams. Front Chem Sci Eng 11(3):328-337. https://doi.org/10.1007/s11705-017-1646-y

Sun X, Cheng P, Wang H, Xu H, Dang L, Liu Z, et al (2015) Activation of graphene aerogel with phosphoric acid for enhanced electrocapacitive performance. Carbon 92:1-10. https://doi.org/10.1016/j.carbon.2015.02.052

Tabaraki R, Sadeghinejad N (2017) Biosorption of six basic and acidic dyes on brown alga Sargassum ilicifolium: optimization, kinetic and isotherm studies. Water Sci Technol 75(11):2631-2638. https://doi.org/10.2166/wst.2017.136

Tan IAW, Ahmad AL, Hameed BH (2008) Adsorption of basic dye on high-surface-area activated carbon prepared from coconut husk: Equilibrium, kinetic and thermodynamic studies. J Hazard Mater 154(1-3):337-346. https://doi.org/10.1016/j.jhazmat.2007.10.031

Temkin, MJ, Pyzhev, V (1940) Recent modifications to Langmuir isotherms. Acta Physicochim URSS. 12:217-225.

Teng H, Yeh TS, Hsu LY (1998) Preparation of activated carbon from bituminous coal with phosphoric acid activation. Carbon 36(9):1387-1395. https://doi.org/10.1016/S0008-6223(98)00127-4

Vladov DCH, Raicheva LP, Nikolov RN, Radoykova THR, Nenkova SK (2019) Preparation of Efficient Carbonaceous Material (Active Carbon) from Hydrolysed Lignin Through Direct Activation with Phosporic Acid. Cell Chem Technol 53(7-8):731-738. https://doi.org/10.35812/CelluloseChemTechnol.2019.53.71

Wang B, Li Y, Si H, Chen H, Zhang M, Song T (2018) Analysis of the Physical and Chemical Properties of Activated Carbons Based on Hulless Barley Straw and Plain Wheat Straw Obtained by H3PO4 Activation. Bioresources 13(3):5204-5212.

Wu Z, Zhong H, Yuan X, Wang H, Wang L, Chen X, et al (2014) Adsorptive removal of methylene blue by rhamnolipid-functionalized graphene oxide from wastewater. Water Res 67:330-344. https://doi.org/10.1016/j.watres.2014.09.026

Yang Q, Wu P, Liu J, Rehman S, Ahmed Z, Ruan B, et al (2020) Batch interaction of emerging tetracycline contaminant with novel phosphoric acid activated corn straw porous carbon: Adsorption rate and nature of mechanism. Environ Res 181:108899. https://doi.org/10.1016/j.envres.2019.108899

Yang S, Wu Y, Wu Y, Zhu L (2015b) Optimizing decolorization of Acid Fuchsin and Acid Orange II solution by MnO2 loaded MCM-41. J Taiwan Inst Chem Eng 50:205-14. https://doi.org/10.1016/j.jtice.2014.12.023

Yang SX, Wu YH, Wu YY, Zhu L (2015a) Optimizing decolorization of Acid Fuchsin and Acid Orange II solution by MnO2 loaded MCM-41. J Taiwan Inst Chem E. 50:205-214 https://doi.org/10.1016/j.jtice.2014.12.023

Yang Z, Yang Y, Zhu X, Chen G, Zhang W (2014) An Outward Coating Route to CuO/MnO2 Nanorod Array Films and Their Efficient Catalytic Oxidation of Acid Fuchsin Dye. Ind Eng Chem Res 53(23):9608-9615. https://doi.org/10.1021/ie500358p

Yin X, Zhang F, Zhang W (2015) Fabrication of hybrid magnetic Sr5Ba3(PO4)3(OH)/Fe3O4 nanorod and its highly efficient adsorption performance for acid fuchsin dye. Appl Surf Sci 359:714-22. 
https://doi.org/10.1016/j.apsusc.2015.10.162

Zeng Z, Ye S, Wu H, Xiao R, Zeng G, Liang J, et al (2019) Research on the sustainable efficacy of g-MoS2 decorated biochar nanocomposites for removing tetracycline hydrochloride from antibiotic-polluted aqueous solution. Sci Total Environ 648:206-217. https://doi.org/10.1016/j.scitotenv.2018.08.108

Zhang B, Wu Y, Fang P (2019) Bamboo charcoal modified with Cu2+ and 3-aminopropyl trimethoxy silane for the adsorption of acid fuchsin dye: Optimization by response surface methodology and the adsorption mechanism. J Appl Polym Sci 136(27):47728. https://doi.org/10.1002/app.47728

Zhang C, Song Z, Shi H, Fu J, Qiao Y, He C (2017) The Effects of Pre-treatments and Low-temperature Pyrolysis on Surface Properties of Biochar from Sunflower Straw as Adsorption Material. Bioresources 12(1):1041-1051. https://doi.org/10.15376/biores.12.1.1041-1051

Zhang T, Xin X, Liu H, Song N, Wang Y, Shi Y, et al (2020a) Sol-gel preparation of spherical gamma-Al2O3 with macro-mesopores as an efficient adsorbent for acid fuchsin. Micro Nano Lett 15(14):1017-1022. https://doi.org/10.1049/mnl.2020.0271

Zhang TT, Xin XL, Liu HQ, Song N, Wang Y, Shi YG, et al (2020b) Sol-gel preparation of spherical gamma-Al2O3 with macro-mesopores as an efficient adsorbent for acid fuchsin. Micor Nano Lett 15(14):1017-1022. https://doi.org/10.1049/mnl.2020.0271

Zhang L, Zhou XY, Guo XJ, Song XY, Liu XY (2011) Investigation on the degradation of acid fuchsin induced oxidation by $\mathrm{MgFe} 2 \mathrm{O} 4$ under microwave irradiation. J Mol Catal A-Chem 335(1-2):31-37. https://doi.org/10.1016/j.molcata.2010.11.007

Zhou R, Zhou R, Zhang X, Bazaka K, Ostrikov K (2019) Continuous flow removal of acid fuchsine by dielectric barrier discharge plasma water bed enhanced by activated carbon adsorption. Front Chem Sci Eng 13(2):340-349. https://doi.org/10.1007/s11705-019-1798-z 